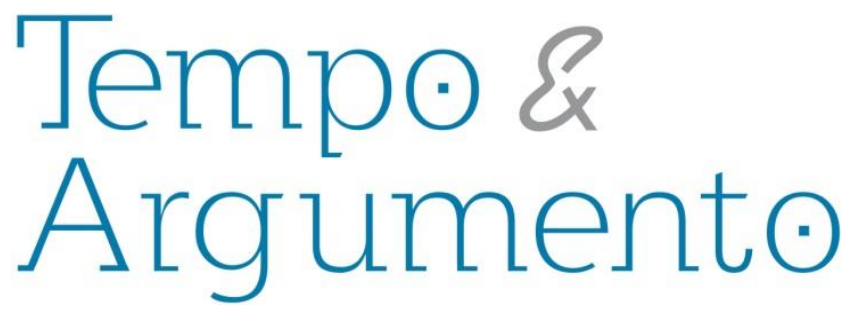

\title{
¿Autónomos o autómatas?: el terrorismo de estado desde la voz de sus partícipes. Argentina y Uruguay (1994-1996)
}

\begin{abstract}
Resumen
Este artículo indaga la emergencia de relatos militares en Argentina y Uruguay durante el período 1994-1996; y lo hace desde dos dimensiones. La primera de ellas tiene que ver con las apreciaciones que hizo la oficialidad militar joven en torno a los niveles de obediencia y autonomía que condicionaron su participación en el terrorismo de Estado, mientras que la segunda explora las percepciones que forjaron sobre la legalidad e ilegalidad de las tareas que llevaron adelante. Se asume, a modo de conclusión, que a partir del estudio combinado de ambas dimensiones es posible entrever procesos particulares de subjetivación de los agentes de represión en Argentina y Uruguay.
\end{abstract}

Palabras clave: Perpetradores. Terrorismo Argentina. Terrorismo - Uruguay. Víctimas del Terrorismo do Estado. Oficialidad Joven.

\author{
Analía Goldentul \\ Instituto de Estudios de América \\ Latina y el Caribe (IEALC). Facultad de \\ Ciencias Sociales de la Universidad de \\ Buenos Aires (FSOC). becaria doctoral \\ del Consejo Nacional de \\ Investigaciones Científicas y Técnicas \\ (CONICET). \\ Buenos Aires - ARGENTINA \\ agoldentul@yahoo.com.ar
}

\section{Para citar este artículo:}

GOLDENTUL, Analía. ¿Autónomos o autómatas?: el terrorismo de estado desde la voz de sus partícipes. Argentina y Uruguay (1994-1996). Tempo e Argumento, Florianópolis, v. 9, n. 22, p. 288 315, set./dez. 2017. 


\title{
¿Autonomous or automatons
}

?: State terrorism from the voice of its participants. Argentina and Uruguay

\section{(1994-1996)}

\begin{abstract}
This article seeks to analyse the emergence of military witnesses in Argentina and Uruguay during the period 1994-1996; and does so from two dimensions. The first has to do with the findings made by the young military officers around the levels of obedience and autonomy that conditioned their participation in state terrorism, while the second one explores the perceptions that they forced about the legality and illegality of the tasks carried out. It is assumed, as a conclusion, that from the combined study of both dimensions is possible glimpse specific processes of subjectivation of the agents of repression in Argentina and Uruguay.
\end{abstract}

Keywords: Terrorism-Argentina. Terrorism-Uruguay. Victims of state terrorismo. Young officer.

La literatura existente sobre los agentes de represión se ha centrado principalmente en el rol que tuvieron los altos mandos de las FF.AA en la planificación del terrorismo de estado. Tanto en Argentina como en Uruguay un caudal importante de investigaciones académicas y periodísticas nos han acercado desde distintos ángulos a las caras más visibles y emblemáticas de la represión. ${ }^{1}$ Sin embargo, pocos estudios se han detenido en el accionar de aquellos oficiales ubicados en los escalafones más bajos de la organización militar. En tal dirección, son muchos los aspectos que aún permanecen

\footnotetext{
${ }^{1}$ En el caso de Argentina, existen numerosos trabajos periodísticos sobre los miembros de la Junta Militar. Seoane. M y Muleiro, V. El dictador: la historia secreta y pública de Jorge Rafael Videla, Buenos Aires: Del Bolsillo, 2012; Uriarte. C. Almirante Cero: Biografía no autorizada de Emilio Eduardo Massera, Buenos Aires: Planeta, 1992. En el caso de Uruguay se destacan Lessa, A. La primera orden: Gregorio Álvarez el militar y el dictador. Una historia de omnipotencia, Montevideo: Editorial Sudamericana, 2009; y Pernas. W. La caída. El dictador Bordaberry y su canciller presos, Montevideo: Ediciones Cauce, 2006.
} 
inexplorados: ¿Qué sentidos le asignaron los cuadros inferiores a los crímenes que cometieron? ¿Sus concepciones de violencia y del "enemigo interno" difirieron de las sostenidas por los altos mandos? ¿Existieron distintos niveles de conocimiento y de convencimiento al interior de la oficialidad joven? ¿Cómo se pensaron y posicionaron en el espacio social antes, durante y después del terrorismo de Estado?

Aunque el abanico de preguntas es amplio y amenaza con extenderse, este articulo analiza en particular la mirada retrospectiva que los oficiales de rango bajo y medio desarrollaron de su accionar represivo en dos países, como Argentina y Uruguay, con experiencias de terror y trayectorias democráticas muy distintas. El conjunto de relatos en primera persona que aquí se analiza tuvo lugar entre 1994 y 1996, una década después de acontecido el terrorismo de Estado. Esta distancia temporal con la vivencia nos obliga a aceptar, como señala Salvi (2010), "que la coincidencia entre el sujeto de la experiencia y el sujeto de la narración está perdida" y que, en virtud de tal extrañamiento, lo que interesa no es reconstruir los "hechos fácticos" a través de la palabra de los militares, sino examinar sus narrativas a la luz de las condiciones jurídico-políticas en que fueron enunciados.

De este modo, un primer eje que atraviesa la lectura de los relatos refiere a la agentividad de los perpetradores, a cómo pensaron su capacidad de agencia al momento de narrar su rol en dictadura. ¿Se representaron como sujetos obedientes, determinados por la cadena de mando y por las estructuras de represión? O, de lo contrario, ¿se proyectaron como agentes con capacidad de decisión y acción sobre los propios actos que perpetraron? Esta pregunta reviste especial interés para el caso de Argentina, que hacia 1994 llevaba siete años de vigencia de la Ley de Obediencia Debida.

Un segundo eje explora la capacidad reflexiva de estos agentes en torno al carácter ilegal de los actos que cometieron. Entre los factores que inciden en este ejercicio debemos hacer mención, en primer lugar, de los específicos modos en que se institucionalizó el terror en Argentina y Uruguay, con entramados represivos que exhibieron distintas articulaciones de lo legal y lo ilegal; y en segundo lugar, la presencia o ausencia del Estado para investigar los hechos del pasado reciente, elaborar una verdad pública y condenar penalmente a los responsables. 
Por último, si el sujeto -al igual que la experiencia- es inexistente por fuera del texto, resulta interesante preguntarnos por las estrategias de auto-representación que están presentes en los relatos que hilvanaron los agentes de represión; cómo se entrelazaron las percepciones sobre la agentividad/pasividad y la legalidad/ilegalidad de su participación en el terror al momento de pensar quiénes eran y qué habían hecho.

\section{Entre la obediencia y la autonomía.}

Durante las dictaduras institucionales de las FF.AA (Ansaldi; Giordano, 2012) en Argentina (1976-1983) y Uruguay (1973-1985) se desplegaron un conjunto de mecanismos, dispositivos y tecnologías de terror que apuntaron a combatir y eliminar al enemigo subversivo. En cada espacio nacional la Doctrina de Seguridad Nacional se materializó en formas particulares de represión. En Argentina la sistematicidad del terror dejó un saldo de miles de desaparecidos, mientras que en Uruguay la persecución política fue más individualizada, los asesinatos se contaron en centenares y el modus operandi no fue tanto la desaparición sino la prisión prolongada (FEIERSTEIN, 2009). En ambos casos, sin embargo, se organizaron células represivas con miembros de las distintas fuerzas, que tuvieron a cargo las operaciones de secuestro, tortura, asesinato y/o desaparición de las víctimas. Si bien los grupos de tareas terminaron convirtiéndose en un símbolo del terrorismo de estado, al principio sus acciones y la pertenencia institucional de las mismas resultaron inasibles para gran parte de la ciudadanía, especialmente para aquellos sectores directamente afectados por la violencia estatal. Precisamente, a raíz del secuestro de su hija, Emilio Mignone² escribía en 1976 una carta abierta a la Junta Militar donde ponía tempranamente de manifiesto ciertas disyuntivas a la hora de pensar la actuación de los militares de bajo rango:

O estos miles de presos detenidos por hombres en actividad de las Fuerzas Armadas están bajo su jurisdicción y entonces toda la jerarquía militar miente (...) o los comandos que actúan de esta manera no están subordinados a sus mandos y entonces la situación es gravísima. Calcule usted las consecuencias y la responsabilidad histórica de quienes ascendieron al poder el 24 de marzo con la bandera del monopolio del poder (...) y a los pocos meses no pueden controlar ni a un suboficial (Carta de Emilio Mignone, citada en VERBITSKY, 1995, p.45)

\footnotetext{
${ }^{2}$ Emilio Mignone fue el fundador y primer presidente del Centro de Estudios Legales y Sociales (CELS)
} 
Hacia fines de 1979, con la visita al país de la Comisión Interamericana de Derechos Humanos (CIDH), se revitalizaron las disputas al interior de la institución militar en torno a la adjudicación de responsabilidades. El entonces Comandante en Jefe de las FF.AA, Jorge Rafael Videla, intentó explicar algunos casos de desaparición esbozando una precaria “teoría de los excesos" (JENSEN, 2010) que hacía foco en la insubordinación de los cuadros inferiores y en el carácter sádico de su accionar (SALVI, 2012a). Como contrapartida, el general Santiago Omar Riveros³ señaló en el diario La Prensa, el 28 febrero de 1980, que la formación de comandos especiales había sido una decisión de los altos mandos que optaron por una estrategia de lucha descentralizada. Según su mirada, si bien era cierto que los cuadros inferiores habían gozado "de un ilimitado poder en cuanto a sus facultades para eliminar a los terroristas o sospechosos de serlo", ese margen de autonomía había sido habilitado y reverdecido por la cúpula militar (La Prensa, 28 de febrero de 1980). 4

Ya en democracia, el Juicio a las Juntas Militares, en 1985, terminó por transformar las disputas previas en un conflicto abierto entre la jerarquía militar y los oficiales subalternos. La contienda no se fundamentó, como en otras veces, en divisiones políticas o ideológicas (Martin, 2010) sino que lo que entró en tensión fue la estructura orgánica de las FF.AA, es decir, la cadena de mando. Los ex comandantes y algunos generales de

32Durante el autodenominado Proceso de Reorganización Nacional (1976-1983), Santiago Omar Riveros se desempeñó como Comandante del Cuerpo IV de Ejército. Desde ese cargo, tuvo bajo su jurisdicción diversos centros clandestinos de detención, entre ellos el Campito y el hospital militar de Campo de Mayo. En 1985 fue condenado por delitos de lesa humanidad pero luego fue beneficiado con los indultos concedidos por el entonces presidente Carlos Menem. Finalmente, en 2009, luego de que la justicia considerada inconstitucional el indulto que le fuera antes concedido, Riveros fue juzgado y condenado por el homicidio de Floreal Avellaneda, un militante de la Juventud Comunista.

${ }^{4}$ Esta estrategia descentralizada de la que hace mención Riveros se hizo pública el 17 de diciembre de 1976 cuando el Ejército oficializó el Reglamento RC-9-1: Operaciones contra elementos subversivos del Ejército. Como señala Slatman, en este reglamento se detallaba la necesidad de implementar una centralización en el plano estratégico (con directivas y propósitos generales) y una descentralización a nivel táctico: "la ejecución de las detenciones será descentralizada al máximo en el ambiente operacional subversivo, que plantea pequeñas y múltiples situaciones fugaces, en espacios mayores que los normales" (RC-9-1: pág. 86). Ello nos da la pauta, según la autora, del grado de autonomía con que se organizaron los distintos organismos de ejecución para combatir la llamada "subversión". Véase Slatman, Melisa, "Una doctrina contrarrevolucionaria para el ejército argentino. Análisis de la discursividad oficial del Ejército Argentino durante la Guerra Fría (1957-1976)", en García Ferreira, Roberto (comp.) Guatemala y la Guerra Fría en América Latina (1947-1977), Guatemala, CEUR-USAC, 2010 
primera línea acusaron a sus subordinados de haber cometido excesos 5 , mientras éstos últimos afirmaron haber sido meros ejecutores de órdenes que emanaban de los altos mandos. En el marco de esta disputa, un locuaz Massera alegó ante los jueces que "no porque el almirante de la orden es que se [iban] a ejecutar las operaciones, sino porque los de abajo [querían] ejecutarlas" (EMILIO MASSERA, Juicio a las Juntas, 1986).

Por su parte, el entonces presidente Raúl Alfonsín había dejado entrever en varias de sus intervenciones públicas una mirada favorable hacia el principio de obediencia debida como modo plausible de explicar el accionar criminal de los cuadros inferiores. En sus propios términos, había que "ofrecer la oportunidad de servir lealmente a la democracia constitucional a aquellos miembros de las Fuerzas Armadas y de Seguridad que no habían actuado por propia iniciativa al participar en actos lesivos de la dignidad humana" (Raúl Alfonsín, citado en CRENZEL, 2008). Esta matriz de pensamiento, en principio rechazada por un Congreso dispuesto a juzgar a todos los oficiales sin distinción de rango, logró finalmente cristalizarse en junio de 1987 -dos meses después del primer levantamiento carapintada- con la sanción de la Ley 23.521 de "Determinación del Alcance del Deber de Obediencia", conocida como Ley de Obediencia Debida.

Este alto grado de conflictividad que atravesó la institución castrense desde 1983 en adelante se configuró en un factor clave para comprender las numerosas intervenciones de militares de rango bajo e intermedio en el espacio público. Las mismas se dieron en coyunturas específicas y a través de soportes diversos (televisión, radio, revistas, diarios, libros autobiográficos, etc.), habilitando con ellas nuevas dimensiones del pasado reciente.

Esta situación halló su reverso en Uruguay con la firma del Acuerdo del Club Naval en 1984. Dicho pacto, a más de sentar las bases para una transición acordada entre la elite política y el poder militar, allanó el terreno para que dos años más tarde se sancionara la Ley de Caducidad de la Pretensión Punitiva del Estado. Funes (2001) señaló la paradoja de

\footnotetext{
${ }^{5}$ Aunque se trató de un conflicto bastante polarizado, es menester señalar que no todos los altos mandos de las FF.AA se alinearon en la estrategia de acusar a sus subordinados por "excesos". Tal es el caso del Almirante Oscar Franco, máxima autoridad de la Armada entre 1982 y 1983, que en 1983 se opuso a esta teoría por considerar que "la responsabilidad por las órdenes impartidas (...) es exclusiva de las autoridades militares" y quienes las cumplieron "están exentos de toda responsabilidad" (citado en Franco, 2014: 6). Sin embargo, como señaló Marina Franco, esta postura expresaba una reivindicación del núcleo ideológico de la dictadura antes que una defensa del accionar de los militares de menor rango.
} 
una transición "impecable" desde el punto de vista de los modelos politológicos (recuperación de la tradición partidaria, incorporación de la izquierda en los acuerdos, alternancia de signo político en las elecciones) que, sin embargo, solo fue posible a condición de amputar el tratamiento de los derechos humanos.

En el marco de esta transición tan "impecable" (FUNES, 2001) como “conservadora" (ANSALDI, 2007) la institución militar evitó verse envuelta en conflictos internos. Marcando distancia con la actitud asumida por la jerarquía militar argentina durante el Juicio a las Juntas, en 1986 los jefes de las tres fuerzas emitieron una declaración que fue leída por el entonces presidente Julio Sanguinetti ante el Congreso, en la que reconocieron una "pérdida de los puntos de referencia" en la conducción y conducta militar entre 1973 y $1985^{6}$. Sostuvieron, asimismo, que el accionar de los cuadros subalternos debía ser situado en ese marco de desorientación, y que la responsabilidad ante cualquier hecho cometido debía recaer en ellos, las autoridades máximas de las FF.AA (Declaración militar de los tres Comandantes en Jefe de las FF.AA, 1986). En continuidad con esta declaración, en 1991 el último comandante en jefe del Ejército durante la dictadura, el Teniente General Hugo Medina, volvió a reivindicar el principio de autoridad en un reportaje que le hiciera el Semanario Búsqueda, en la que además admitió haber dado órdenes de tortura (Semanario Búsqueda, 7 de marzo de 1991)

Sobre la base de este fuerte hermetismo y cohesión interna de las FF.AA uruguayas, fueron excepcionales las veces en que los agentes de represión tomaron la palabra. En general, ni los altos o bajos mandos se expusieron públicamente ni su voz fue demandada social o políticamente más que por aquellos organismos de derechos humanos que persistieron en su lucha por averiguar el destino de los desaparecidos?.

A pesar de estas sustanciales diferencias entre casos nacionales, al promediar la década del noventa fue posible registrar en ambas orillas del Río de la Plata la aparición pública de varios militares que habían tenido actuación en dictadura, luego de un período marcado por la impunidad jurídica, el alejamiento de los medios de comunicación hacia los temas del pasado (FELD, 2001) y la progresiva pérdida de convocatoria en los actos y marchas de la memoria. La nueva coyuntura se desencadenó en octubre de 1994 cuando

\footnotetext{
${ }^{6}$ Esta declaración distó de ser una "autocrítica" o un pedido de perdón institucional. Tampoco implicó un reconocimiento de los crímenes cometidos por las FF.AA durante la última dictadura militar.

7 De acuerdo al Informe "Uruguay, nunca más", hay un total de 140 personas detenidas-desaparecidas, de las cuales la mayoría tuvo lugar en el marco del Plan Cóndor.
} 
los pliegos con los ascensos de dos oficiales de la Armada Argentina, Juan Carlos Rolón y Antonio Pernías, fueron sometidos a un debate público en el Congreso de la Nación. Durante el autodenominado Proceso de Reorganización Nacional (1976-1983), Juan Carlos Rolón tuvo el grado de capitán de corbeta y se desempeñó como integrante del grupo de tareas 3.3.2 de la Escuela Mecánica de la Armada (ESMA) ${ }^{8}$. Antonio Pernías, por su parte, ocupó el grado de teniente de fragata e integró el mismo grupo de tareas que Rolón.

Las declaraciones de Rolón y Pernías en el Congreso Nacional sentaron un precedente clave en tanto fue la primera vez que dos militares en servicio confesaron ante la clase política dirigente que habían causado tormentos durante el terrorismo de Estado. Si bien ambos marinos se esforzaron en remarcar que durante el proceso militar se limitaron al cumplimiento de órdenes, el rechazo del Senado a concederles la promoción reavivó los límites políticos, culturales y simbólicos de la ley 23.521. Ciertamente, la "verdad jurídica" 9 instalada a partir de la ley de obediencia debida estaba lejos de haberse transformado en una "verdad histórica", no pudiendo modificar las imágenes, representaciones y estereotipos que vastos sectores de la sociedad civil y política habían empezado a construir desde 1983 sobre los agentes de represión estatal; ni mucho menos extender sus efectos de verdad a los organismos de derechos humanos que permanecían firmes tras la consigna de "juicio y castigo a todos los culpables".

La negativa del Senado motivó a su vez la irrupción pública de otros partícipes del terrorismo de Estado. Así, en marzo de 1995 el capitán de corbeta (R) Adolfo Scilingo relató en forma extensiva ante el periodista Horacio Verbitsky su participación en los llamados "vuelos de la muerte". Y más tarde, en el mes de abril, el ex cabo del Ejército Víctor Ibáñez, hizo lo propio en el diario La Prensa al contar su experiencia como celador del centro clandestino El Campito ${ }^{10}$. Estas declaraciones, sobre todo las de Scilingo, interpelaron al entonces Jefe del Estado Mayor del Ejército argentino, el General Martín

\footnotetext{
${ }^{8}$ El Grupo de Tareas 3.3.2 (G.T.3.3.2) fue un grupo de tareas constituido por suboficiales y oficiales militares, que dependía del Servicio de Inteligencia Naval (SIN), dedicado al secuestrado, tortura y desaparición de personas. Este grupo operó en el seno de la Escuela Mecánica de la Armada y alojó en su seno a algunos de los perpetradores más emblemáticos de la represión ilegal, como Alfredo Astiz, Jorge Acosta, Ricardo Cavallo, Adolfo Donda y Juan Antonio Azic.

9 Sobre la diferencia entre la verdad histórica y la verdad jurídica, recomiendo la lectura de Vezzetti, Hugo (2014). "Verdad jurídica y verdad histórica. Condiciones, usos y límites de la figura del genocidio" en Hilb, C, Saazar, P. J y Martín, L (eds.). Lesa Humanidad. Argentina y Sudáfrica: Reflexiones después del Mal, Buenos Aires: Katz, 2014

${ }^{10}$ El "Campito" fue uno de los cuatro centros clandestinos de detención (CCD) que funcionó dentro de la guarnición militar de Campo de Mayo, bajo la órbita del Ejército.
} 
Balza, a realizar una "autocrítica" de la actuación militar y a echar por tierra los fundamentos sobre los cuales se amparaba la Ley de Obediencia Debida. En este discurso transmitido en vivo por televisión"1, Balza señaló que ningún oficial había estado "obligado a cumplir una orden inmoral" y que aquellos que efectivamente habían incurrido "en una conducta viciosa" debían ser sancionados (Autocrítica del General Martín Balza, 25 de abril de 1995).

Esta concatenación de hechos tuvo gran repercusión en el país vecino y ayudó a resquebrajar el silencio prácticamente incólume que hasta entonces había caracterizado a los militares uruguayos. En 1996 el General (R) Alberto Ballestrino describió en un reportaje las redes, logias y diputas que envolvían a los militares de alto rango y más tarde, en una entrevista hecha por la revista Posdata, dos agentes con identidad reservada proporcionaron algunos nombres de cuadros subalternos que habían formado parte de la represión clandestina. En respuesta a dichos señalamientos, uno de los agentes mencionado, Jorge Néstor Tróccoli, publicó en mayo de ese año una carta abierta en el diario El País con el título Yo asumo, yo acuso, en la que reconoció su participación en el terror. A esta primera carta se adicionó luego un libro ${ }^{12}$ y una entrevista radial ${ }^{13}$.

En este escenario en el que los asuntos del pasado recuperaron visibilidad a través de la voz de los perpetradores, se entremezclaron miradas diversas sobre las dinámicas que rigieron al interior de estos entramados represivos. En el caso de Argentina, frente a una ley que iba perdiendo el sustento político que la hizo posible, los relatos de militares y policías que tuvieron lugar en este período tendieron a reafirmar el principio de obediencia como marco explicativo de su participación en la represión. En palabras de Ibáñez:

11 La declaración de Balza tuvo lugar en el programa televisivo Tiempo Nuevo, dirigido por Bernardo Neustadt.

${ }^{12}$ El libro se publicó en 1996 con el título La ira de Leviatán: del método de la furia a la búsqueda de la paz. A lo largo de las 144 páginas, Tróccoli narra su ingreso a la carrera militar, su mirada del pasado reciente y realiza una serie de entrevistas, tanto a militares que actuaron en dictadura como a ex miembros de distintas organizaciones armadas.

13 El 23 de septiembre de 1996 el periodista Emiliano Cotelo le hizo una entrevista a Tróccili para su programa radial "En Perspectiva”, en la Radio El Espectador. La entrevista se iba a desarrollar en un solo día pero el interés que despertó la figura del marino retirado en el periodista y en la audiencia motivaron una segunda entrevista al día siguiente. 
Si te tocaba no podías zafar, porque también eras boleta. Muchos de mis compañeros fueron pasados por las armas ante la mínima sospecha de resistencia a participar en estas cosas. Yo me acuerdo de un suboficial principal que trabajaba en el Hospital Militar; era un hombre grandote, colorado. Nunca más se supo de él (Víctor Ibáñez, La Prensa, 25 de abril de 1995).

Aunque la obediencia emergió como un elemento común y aglutinante de los relatos, no fue posible encontrar un único sentido atribuido a este principio. Mientras en la palabra de Ibáñez la obediencia apareció como una vía legítima para evitar la muerte y las amenazas internas, en las declaraciones de Pernías y Scilingo fue referida como una expectativa o norma de comportamiento inherente a toda organización militar:

Por la jerarquía que yo tenía en ese momento no poseía ningún tipo de decisión sobre el tema (Antonio Pernías, citado en Verbitsky, 1995, p.79)

Si usted está dentro de una organización armada, siempre recibe órdenes, cumple órdenes o da órdenes (... Cuando se recibía la orden no se hablaba más del tema. Se cumplía en forma automática (...) (Adolfo Scilingo, citado en Verbitsky, 1995, p.18)

Esta forma de narrar el rol que tuvieron en dictadura, empleando una oratoria fuertemente normalizada y abroquelada en torno al cumplimiento de las órdenes, se diferenció de las declaraciones que hizo en 1984 el ex marino Raúl Vilariño en la revista La Semana, cuando manifestó que su incorporación a una de las patotas de la ESMA había sido un acto voluntario y que el grupo que "él manejaba" tenía "cierta autonomía”"14. En las declaraciones que tuvieron lugar a mediados de los noventa, en cambio, todo indicio de autonomía fue obliterado en pos de alcanzar un relato coherente donde la narración de las experiencias vividas no hizo sino confirmar "fácticamente" la verdad jurídica de 1987. Aun así, la reconstrucción que estos militares o ex militares hicieron de sí mismos

\footnotetext{
${ }^{14}$ Con el título "Yo secuestré, maté y vi torturar en la Escuela Mecánica de la Armada", la entrevista al ex suboficial de marina que le hizo la revista La Semana, en enero de 1984, se ofrecería como una de las primeras aproximaciones públicas a esa faz clandestina del terrorismo estatal desde la voz de sus partícipes más directos. Según su palabra, "la incorporación era voluntaria (...) Algunos fuimos llamados por nuestra preparación o nuestra forma de pensar. Pero se nos consultaba si queríamos entrar". Más aún, en esta primera entrevista Vilariño se referiría al cumplimiento de órdenes superiores como un principio "relativo", no estricto, que debía ser matizado: “(...) eso de cumplir las órdenes es muy relativo. Por ejemplo, al principio fue voluntario; se cumplían órdenes voluntariamente. Pero, después, por temor a no seguir viviendo, se siguieron cumpliendo aunque involuntariamente".
} 
la cadena de mando, la mayoría expresó un "total convencimiento" hacia el combate contra la "subversión".

Lo cumplí como un acto de servicio, convencido de lo que hacía y, sobre todo, de que de esa manera podríamos lograr restablecer el estilo de vida democrático de la Argentina (Juan Carlos Rolón, citado en Verbitsky, 1995: 82)

Yo no dudé nunca de lo que se estaba haciendo ahí. (...) Estaba totalmente compenetrado con la carrera. Era algo que había que hacerlo. Hoy le digo que fue una barbaridad. En ese momento estábamos totalmente convencidos de lo que hacíamos (Adolfo Scilingo, citado en Verbitsky, 1995, '.p.16)

De este modo, lejos de la figura del "autómata" o del simple engranaje de una maquinaria burocrática que había cumplido las órdenes sin cuestionarse su naturaleza criminal, muchos de estos agentes expresaron decisión y convicción en torno al accionar antisubversivo y a los métodos empleados. En efecto, Vezzetti (2002) planteó la dificultad de pensar el caso argentino desde las tesis de Hannah Arendt sobre la banalidad del Mal, al considerar que pese a la división de tareas, el carácter rutinario del aparato represivo o al fuerte verticalismo que atravesó a la organización militar, los cuadros intermedios e inferiores de la dictadura gozaron de cierta autonomía relativa en su accionar. Y, lo que es más relevante aún, tendieron a justificar su modus operandi, ya no desde razones banales sino a partir de un sistema articulado de creencias que combinó elementos provenientes del canon de la Iglesia católica, de la Doctrina de Seguridad Nacional y de la Escuela Contrarrevolucionaria francesa. Por tal razón, el autor postula como rasgo específico del represor argentino -y latinoamericano- su carácter fuertemente ideologizado, marcando distancia con la banalizada figura del agente nazi.

Ello ciertamente logró entroncarse con lo que describe Salvi (2012b) sobre los oficiales del Ejército que participaron del Operativo Independencia ${ }^{15}$, para quienes la

\footnotetext{
${ }^{15}$ El Operativo Independencia fue una acción militar sostenida del Ejército sobre el monte tucumano, que tuvo lugar entre febrero y septiembre de 1975. La intervención fue habilitada por el gobierno de María Estela Martínez de Perón mediante el decreto de aniquilamiento N²62/75. Si bien el principal objetivo
} 
que formaron parte de la represión ilegal a partir de 1976, la obediencia emergió como un registro de justificación que vertebró y cohesionó la narración del pasado, mientras que el convencimiento ideológico, por el contrario, tuvo distintos grados o intensidades. Observemos, a continuación, el modo en que el ex cabo Víctor Ibáñez describía al “enemigo" de la lucha antisubversiva:

Era una época intensa: todos los días mataban a uno de los nuestros. Yo creía que ellos eran realmente nuestro enemigo y que había que combatirlos. (... Había una guerra, sí. Y yo me había preparado para ella. Estaba entrenado para combatir en Tucumán, quería ir a Tucumán a combatir a la guerrilla. De uniforme, frente a un enemigo visible que también te tira. Pero en cambio me mandaron a 'El Campito'. Con el tiempo ya no estaba tan convencido de que así se defendiera a la Patria. (Víctor Ibáñez, La Prensa, 25 de abril 1995)

En este relato, el tránsito de un estadio de compromiso pleno hacia una etapa de creciente escepticismo o decepción frente al tipo de lucha planteada, nos permite entrever que, lejos de rememorar la dictadura como un proceso lineal o monocorde, algunos perpetradores dicen haber experimentado cambios en las formas de pensar y encarar la represión ilegal. Recuperamos aquí a Salvi (2016) cuando sugiere desafiar y matizar la diametral oposición entre agencia y estructura, entre el verdugo autónomo, firme y convencido y el burócrata mediocre, para pensar en formas vernáculas de represión que articularon distintos niveles de coacción y convicción, de obediencia y autonomía.

Volviendo sobre el relato del ex cabo Ibáñez, en él se pueden distinguir dos etapas. Una primera, en la que la idealización negativa de la figura del subversivo, con determinadas rasgos que acentuaban su peligrosidad, realimentó sus certezas sobre la

del operativo fue eliminar la Compañía Ramón Rosa Jiménez, perteneciente al Ejército Revolucionario del Pueblo (ERP), entre las víctimas no solo se registran integrantes del ERP sino también población local de extracción popular que fue sometida a apremios ilegales y a todo tipo de vejámenes. La mayoría de los especialistas en el tema coincide en que Tucumán fue el ensayo de operaciones y antesala de lo que sería a partir del 24 de marzo de 1976 la acción clandestina y terrorista del Estado en todo el territorio nacional. 
necesidad de eliminar al "enemigo interno". Y una segunda instancia, donde el contacto asiduo con los secuestrados en pésimas condiciones de detención, lo obligó a confrontar las formas a priori con que se había representado al enemigo:

La situación que se me presentó fue al revés de lo que había aprendido en la escuela (...) me presentaban a un enemigo vencido, humillado, y te decían: 'este es tu enemigo'. Una persona atada, encapuchada, torturada. ¿Qué enemigo? A mí me hubiera gustado ser un verdadero soldado" (Víctor Ibáñez, La Prensa, 25 de abril 1995)

Como se desprende de esta cita, el contexto de encierro y de proximidad con el “enemigo" no solo terminó obstaculizando la identificación de Ibáñez con el ideal del "verdadero" soldado; también produjo un socavamiento en los niveles de convencimiento necesarios que exigía la lucha "antisubversiva". Inversamente, la lejanía, la despersonalización de los secuestrados y el desconocimiento de sus identidades, parecieran haber facilitado la acción criminal. Precisamente, cuando Verbitsky le preguntó a Scilingo si al momento de hacer los traslados conocía las trayectorias y nombres de las personas que arrojó al mar, éste respondió negativamente:

No, no. Tampoco me interesaba. Yo estaba confiado totalmente en las decisiones que habían tomado mis superiores (Adolfo Scilingo, citado en VERBITSKY, 1995, p.32)

Las declaraciones de Scilingo tuvieron especial repercusión en Uruguay y, como se mencionó más arriba, motorizó la irrupción de varios militares en los medios de comunicación. Sin embargo, solo uno de ellos, Jorge Néstor Tróccoli, ofreció un relato pormenorizado de su participación en la dictadura. Nacido en 1947, este capitán de navío (R) hizo su carrera en la Escuela Naval y con treinta años de edad se convirtió en el jefe del departamento de inteligencia de Fusileros Navales (FUSNA). Desde ese lugar colaboró activamente en la coordinación represiva entre Montevideo y Buenos Aires, llegando a participar de forma personal en la captura, traslados e interrogatorios de militantes uruguayos y argentinos (BLIXEN, 1996). 
A partir de sus declaraciones, los medios de comunicación uruguayos trazaron un paralelo entre ambos marinos pese a las considerables diferencias que existieron entre ambos. En primer lugar, los efectos políticos que generaron tuvieron distinta magnitud. Si las intervenciones de Scilingo habían interpelado al entonces Comandante en Jefe del Ejército a admitir públicamente los hechos atroces que cometieron las FF.AA durante la dictadura, en Uruguay ninguna de las veces en que Tróccoli tomó la palabra tuvieron un desenlace semejante. Tan solo el Comandante en Jefe de la Armada, el Vicealmirante Raúl Risso, se limitó a decir que los asuntos del pasado reciente estaban cerrados con la Ley de Caducidad y que desde las FF.AA no se produciría ningún gesto de arrepentimiento institucional por lo actuado.

Por otra parte, también se observaron sustanciales diferencias en relación al contenido de los relatos. Scilingo había enfatizado a lo largo de la entrevista concedida a Verbitsky el hecho de haber cumplido órdenes. En los dichos de Tróccoli este marco explicativo aparecía soslayado privilegiándose, en cambio, otros elementos como el "compromiso" con la lucha antisubversiva:

Entrevistador: ¿Usted no pasa por el concepto de obediencia debida? Tróccoli: No, no paso por el concepto de obediencia debida, porque a veces ese concepto no refleja lo que fue la realidad del hecho. Para mí sería muy cómodo decir: "Yo estaba cumpliendo órdenes". Pero eso ya lo hemos escuchado en otras oportunidades. Esto no solamente es cuestión de cumplir órdenes, sino de estar comprometidos con la lucha. (Jorge Néstor Tróccoli, El Espectador, 23 de septiembre de 1996)

Si la apelación al respeto por la cadena de mando tiende a generar efectos representacionales sobre la figura de los agentes de represión como meros “ejecutores”, por el contrario, la exaltación que hizo Tróccoli del compromiso lo llevó a establecer diferencias internas entre aquellos que tuvieron valentía y bravura y aquellos que por su falta de coraje o arrojo no pudieron encarar el combate contra el "enemigo interno":

Unos se comprometen más, otros menos, unos optan por llegar a extremos, otros van llegando a extremos sin darse cuenta y otros no (...) Pero esa gente que no participó en interrogatorios o en extremos o que optó por no hacerlo, también tenía otro rol. No se mantenían al margen de la represión. Eran personas que salían a hacer operativos, que traían a la gente encapuchada, que la registraban y que, si se resistía, ejercían un 
grado de violencia, que después sabían perfectamente todo lo que se estaba haciendo. Pero cuando llegaba el momento de decir "acá hay que profundizar el interrogatorio, se necesita información", esa gente daba un paso atrás. Y estaba en su derecho. (Jorge Néstor Tróccoli, El Espectador, 23 de septiembre de 1996)

Otro elemento que refuerza las diferencias entre casos fue el lugar asignado a la institución militar para explicar la violencia clandestina. Scilingo apuntó en reiteradas veces a la responsabilidad de las FF.AA en la planificación de los crímenes que cometieron los oficiales menos jerárquicos. Ello marcó una diferencia con la narración del marino uruguayo, en la cual fue posible advertir un realzamiento del individuo y de sus capacidades para no dejarse avasallar por las lógicas y dinámicas inherentes a la maquinaria de terror. Es desde esta perspectiva que Tróccoli se refirió a la tortura como una "vivencia” y una "decisión personal”, esto es, como una experiencia a través de la cual los agentes de represión pudieron explorar y reconocer sus propios límites, sin amenazas o presiones internas que mediaran la acción represiva:

Quiero comentar varias cosas. La vivencia de cosas como puede haber sido la tortura es una cuestión netamente personal. No se puede extraer de ninguno de los testimonios una generalización que involucre a todas las Fuerzas Armadas. Hubo mucha gente que no lo vivió y otros que se negaron a vivir esto. Estas son vivencias personales, que es lo que nosotros tenemos que extraer (...). Hubo gente que tal vez pensó que había que llegar hasta determinado lugar y otros que llegaron a otro extremo (...) Hasta qué nivel se llega en la escalada de violencia es un tema personal. (Jorge Néstor Tróccoli, El Espectador, 23 de septiembre de 1996)

Si bien estas declaraciones marcaron distancia con los relatos de sus pares argentinos donde la estructura de represión aparece anulando al individuo y por ende, sobreseyéndolo, la descripción que hizo Tróccoli del aparato represivo como una suma de individualidades con diferentes niveles de iniciativa y de compromiso no debe ser interpretada como una asunción de la responsabilidad personal. De lo contrario, su descripción del aparato represivo como una suma de individualidades genera efectos de sentido que desordenan, dispersan o ponen en cuestión la sistematicidad del terror. 
Como conclusión provisoria, en Argentina nos encontramos con un desarrollo histórico marcado primero por la sanción de la Ley de Obediencia Debida, en 1987, y luego por la "autocrítica” del General Balza, en 1995. En ese marco, los relatos de los agentes de represión exhibieron principalmente dos registros de justificación: la obediencia (como expresión de coacción) y en segundo lugar de importancia, la convicción ideológica (como expresión, quizá, de cierta autonomía). Diferente a lo ocurrido en Argentina, en Uruguay no existió un conflicto político e institucional en torno a la adjudicación de responsabilidades. Los últimos tres comandantes en Jefe de la dictadura defendieron el principio de autoridad y los cuadros subalternos, por su parte, respetaron el pacto de silencio. Sobe la base de esta fuerte cohesión vertical y horizontal de las FF.AA el relato de Tróccoli presentó un solo registro de justificación: el compromiso ideológico.

\section{Percepciones sobre la legalidad e ilegalidad del terror}

Los regímenes de violencia que se desplegaron en el Cono Sur latinoamericano exhibieron formas distintas de institucionalizar el terror. Romero (1994) acuñó el término «Estado desdoblado» para referirse en Argentina a la presencia de una estructura institucional compuesta de dos partes: una visible, pública y ostensiblemente legal y la otra clandestina, ilegal y terrorista. Si bien en este caso la dictadura apeló a distintas estrategias de legitimación y hasta conservó algunos dispositivos legales como la pena de muerte, el grueso de las ejecuciones tuvo lugar en la clandestinidad. Ello marcó un contraste con Uruguay donde la mayor injerencia del Poder Judicial le otorgó cierto viso de legalidad al terrorismo estatal, por ejemplo, a través de órdenes de detención que debían preceder a los secuestros, o bien habilitando la instancia del juicio para condenar penalmente a los detenidos. Mas que “desdoblarse”, el Estado uruguayo ejerció su violencia a partir de una singular imbricación de prácticas legales e ilegales (TCACH; SERVETTO, 2007)

Estas estructuras de violencia fueron percibidas por los militares de manera heterogénea. En el caso de militares argentinos fue posible advertir un mayor reconocimiento del carácter ilegal que envolvió sus prácticas. Esta mayor apertura o 
flexibilización de la palabra probablemente se asentó en las condiciones objetivas en que fueron enunciados los relatos. Mientras Scilingo se sentía "abandonado" y sería en adelante objeto de hostigamientos por parte de sus camaradas y del Estado, Ibáñez había sido dado de baja de las filas del Ejército. Rolón y Pernías, por su parte, aun prestaban servicio en la Armada pero la aprobación de sus ascensos dependía de la decisión mayoritaria de un Senado que estaba especialmente interesado en saber si los marinos poseían la capacidad de discernir entre una orden legal y una orden ilegal ${ }^{16}$. De algún modo, los cuatro oficiales compartían una situación de vulnerabilidad que, es de suponer, los animó a extender los límites de lo decible.

En este marco, Rolón señaló ante los miembros del Senado que "que bajo ninguna circunstancia daría órdenes como las que obedeció" y que éstas habían sido “equivocadas"17, mientras que Pernías remarcó la ausencia de leyes durante la "guerra no convencional":

Yo creo en las leyes de la guerra y las conocí bastante después. Las conocí realmente en Malvinas (...) Esto fue una guerra no convencional. Las leyes fueron acomodadas, tal vez, a los procedimientos que utilizaron las Fuerzas Armadas. Yo creo que no había leyes (Juan Carlos Rolón, citado en VERBITSKY, 1995, p.7)

El ex cabo Víctor Ibáñez, por su parte, afirmó que "en esa época no corrían órdenes oficiales escritas" y que "todo era clandestino" ${ }^{18}$. Y Scilingo, si bien sostuvo que durante la dictadura estaba convencido de haber actuado en cumplimento de órdenes legales, luego el silencio sostenido por la jerarquía militar lo obligó a enfrentar el pasado reciente y a reconocer la naturaleza criminal de los actos perpetrados:

\footnotetext{
16 Esta sesión tuvo lugar el 19 de octubre de 1994. En ella, Ricardo Lafferriere, perteneciente al Partido Radical y Juan Carlos Romero, del Partido Justicialista, tuvieron una participación muy activa y lograron formular una serie de preguntas a Pernías y Rolón que apuntaban a conocer cómo estos marinos pensaban su actuación en dictadura. En el marco de esta conversación que se desarrolló entre los senadores y los dos oficiales de las marina, Lafferriere le dijo a Rolón que para los miembros del Senado era importante "estar absolutamente convencidos de que en ningún caso y bajo ninguna circunstancia, por más difícil que sea, usted como oficial superior de la Marina de nuestro país, daría una orden parecida a aquellas que tuvo que cumplir al inicio de su carrera" (Verbitsky, 1995. p. 85)

17 Declaraciones de Juan Carlos Rolón, citado en Verbitsky, Horario, El vuelo, óp. cit, pág. 7.

${ }^{18}$ La Prensa, 25 de abril de 1995.
} 
Si usted me pregunta qué pienso hoy, es otra cosa, pero en ese momento no tenía ninguna duda. Si hubieran sido órdenes legales nadie tendría vergüenza de decirle a todo el mundo qué pasó, cómo se luchó (...) (Adolfo Scilingo, citado en VERBITSKY, 1995, p.19)

A través de diferentes términos y con alusiones más o menos directas, se observó por parte de estos agentes de represión una tendencia a admitir el carácter ilegal de la represión. En gran medida, esta estrategia resultó inescindible del mayor conocimiento que la sociedad fue adquiriendo sobre el sistema desaparecedor a partir de la transmisión televisiva ${ }^{19}$ y publicación escrita de Nunca Más (1984) y fundamentalmente, del Juicio a las Juntas Militares (1985). Frente a ello, los militares o ex militares de bajo rango que dieron su palabra al promediar la década del noventa difícilmente pudieron negar un conjunto de hechos si no era a condición de perder credibilidad en sus relatos. ${ }^{20}$

También resulta interesante advertir que quienes mostraron menos reparos a la hora de referirse a la ilegalidad de la violencia fueron precisamente aquellos que se anclaron con mayor fuerza en el régimen de obediencia como forma de narrar y justificar lo actuado. Esta correspondencia entre obediencia y reconocimiento de la ilegalidad posiblemente tenga que ver con la auto-percepción que forjaron de sí los agentes de represión como meros "ejecutores” sin decisión sobre los actos propios que, en virtud de ello, podían admitir con mayor facilidad la naturaleza atroz de crímenes que no habían sido planificados por ellos. En esta dirección, si dentro de este conjunto de relatos Scilingo es quien más enfatizó el hecho de haber cumplido órdenes, también fue el que admitió con mayor ahínco el carácter delictivo de los actos perpetrados:

\footnotetext{
19 Los resultados de la investigación que llevó adelante la Comisión Nacional sobre la Desaparición de Personas (CONADEP) no sólo se difundieron con la edición escrita, sino también a través de un programa de televisión que, al igual que el libro, se llamó Nunca Más. La transmisión en vivo tuvo lugar en julio de 1984, con picos de audiencia muy considerables que evidencian la gran difusión que tuvo el programa. Al respecto, véase Crenzel, Emilio (2008). "La investigación de la CONADEP en televisión" en Question, Vol. 1, núm. 18.

${ }^{20}$ Valentina Salvi analiza las declaraciones públicas de Videla desde la dictadura hasta 2012 y observa que en las últimas veces en que el ex comandante en jefe de las FF.AA tomó la palabra, debió incorporar en su discurso "elementos de lo socialmente reconocido sobre la violencia perpetrada por las fuerzas armadas durante el terrorismo de Estado" a fin de generar interés y ser escuchado. Véase Salvi, Valentina (2016). ““"Entelequia”, “enmascaramiento” y “disimulo”. Las últimas declaraciones de Videla sobre los desaparecidos (1998-2012)” en Rúbrica Contemporánea, vol. 5, n¹9.
} 
Inversamente, las declaraciones de Tróccoli enriquecen la comparación por cuanto la forma de pensar su participación en el terrorismo de Estado exhibió fuertes marcas de individuación y autonomía, pero también, una reafirmación del carácter legal de la represión:

Desde entonces sus antiguos subordinados pasamos a ser ejecutores de órdenes que podrían tener carácter delictivo (...) Yo creo que actuamos como delincuentes comunes. Me cuesta mucho aceptarlo, pero los otros me lo demuestran (Adolfo Scilingo, citado en VERBITSKY, 1995, p. 9)

En alusión a los agentes de represión argentinos] Algunos de ellos me preguntaban a mí: "¿Cómo puede ser que en el Uruguay un tipo desaparezca en la calle y aparezca declarando en un Juzgado?". Y yo les decía: "Esa es la solución que adoptamos nosotros". Son cosas que se van dando de acuerdo a la naturaleza íntima de cada una de las naciones. (Jorge Néstor Tróccoli, El Espectador, 23 de septiembre de 1996)

En cierto modo, el mito de la "excepcionalidad” uruguaya, según el cual este país posee una férrea tradición civilista y republicana que lo vuelve equiparable a los países europeos, fue resignificado en el relato de este marino $(R)$ para destacar el carácter único que tuvo la lucha "antisubversiva" en Uruguay, con una violencia que aparentemente exhibió “códigos" y que prescindió de la figura del desaparecido como metodología de terror. Este "apego" a la legalidad ciertamente compuso la trama argumentativa de gran parte de sus reflexiones. Así, cuando se le preguntó por aquellos que se "excedieron" en el cumplimiento de las órdenes, Tróccoli rescató cierto apego a las normas al mencionar los múltiples procesamientos y relevos internos que tuvieron lugar en el interior de las FF.AA, como también la enérgica condena moral que existió entre los compañeros hacia aquellos oficiales que obraron con sadismo o malicia:

Eran fuertemente despreciados y censurados por sus compañeros. Vi como se informaba acerca de ellos y eran relevados de sus cargos (...) Esas cosas no han trascendido, pero hubo gente que fue muchísimo más allá; hubo procedimientos condenables y no estoy hablando en el grado de crueldad sino en la esencia del procedimiento. Esos fueron procesados. (Jorge Néstor Tróccoli, El Espectador, 23 de septiembre de 1996) 
Por otra parte, resultaron sugerentes las comparaciones repetidas con los militares argentinos. Fue justamente en ese contraste entre "ellos" y "nosotros", que el marino destacó ciertos límites y principios inherentes al accionar de los militares uruguayos frente a un estereotipo de oficial argentino que era imaginado sin reparos éticos:

Nosotros mismos, cuando íbamos a detener a alguien, de repente deteníamos a un matrimonio, nos encontrábamos con un bebito, con un niño pequeño, y lo primero que hacíamos era buscar a sus familiares y dárselo (... En Argentina las cosas no fueron así. (Jorge Néstor Tróccoli, El Espectador, 23 de septiembre de 1996)

Estas diferencias en el tratamiento del detenido/desaparecido tuvieron que ver, según el marino retirado, con la naturaleza de los objetivos que se planteó cada régimen de violencia. Mientras en Argentina los militares recibieron la orden de exterminar al “enemigo interno", en Uruguay la orden recibida fue más bien la de "neutralizar las acciones de la subversión":

Nosotros, las Fuerzas Armadas Uruguayas, nunca recibimos una orden de exterminio. Yo no tengo presente en este momento los términos exactos de la orden que recibimos, pero era algo así como "neutralizar" o "evitar las acciones de la subversión. (Jorge Néstor Tróccoli, El Espectador, 23 de septiembre de 1996)

Algo similar afirma Freíd (2001) cuando sugiere que, mientras los militares argentinos buscaron el aniquilamiento físico del "enemigo interno", las FF.AA uruguayas ejercieron un control orwelliano de la población civil, derivando ya no en la figura del desaparecido sino en la del "preso político". Tcach y Servetto (2001), en cambio, sostienen que ambos gobiernos militares tuvieron objetivos y métodos similares pero que en el caso argentino el fin de consolidar un nuevo orden social y político desembocó en una dictadura "fundacional" mientras que en Uruguay el objetivo de custodiar el orden vigente derivó en una dictadura "comisarial". 


\section{Algunos apuntes sobre los procesos de subjetivación de agentes de represión.}

Al igual que las miradas que desarrollaron sobre su participación en el aparato represivo, las estrategias de auto representación que se desprendieron de las declaraciones que hicieron los agentes de represión deben ser situadas en contextos nacionales específicos, con prácticas (movilizaciones, comisiones de verdad, testimonios, escraches) y actores diversos (gobiernos, organismos de derechos humanos, agrupaciones políticas) que reeditaron permanentemente los sentidos construidos sobre los perpetradores. Es sobre la base de esta premisa que elegimos hablar de "procesos de subjetivación" en lugar de "sujetos" en tanto, como sostiene DUBET (1998), mientras este último término "designa una entidad demasiado heroica y metafísica", la subjetivación implica reconocer la producción social de esa ilusión.

En el caso de Argentina, desde la temprana transición se fueron construyendo representaciones estereotipadas y criterios de marcación de los perpetradores en tanto represores ${ }^{21}$. En 1984 la Comisión Nacional sobre la Desaparición de Personas (CONADEP) incluyó en el informe Nunca Más una lista con los nombres de aquellos oficiales que cometieron crímenes de Estado. ${ }^{22} \mathrm{Y}$ al año siguiente, la transmisión en vivo del Juicio a las Juntas Militares permitió que la imagen de los agentes de represión sentados en el banquillo de los acusados llegara a miles de hogares argentinos. Una década más tarde, en 1995, las declaraciones de Scilingo desencadenaron el nacimiento de H.I.J.O.S y luego, en 1997, surgieron las acciones colectivas de escrache con el objetivo de elaborar la condena social y moral de los agentes del terrorismo de estado.

Estas prácticas tienen vital importancia a la hora de reflexionar sobre los procesos de subjetivación de los agentes de represión ya que, como apuntala Ferrarotti, (2007,

\footnotetext{
${ }^{21}$ Frente a expresiones más genéricas como las de “victimario" o “perpetrador", esta categoría evoca figuras, tramas de violencia y terror con un fuerte arraigo local en Argentina. Comenzó a ser utilizada con mayor asiduidad en la década del ' 80 con un sentido bien definido: señalar y condenar la responsabilidad moral y criminal de los agentes del terrorismo de Estado. El inicial encapsulamiento de esta categoría en el actor militar/policial y más recientemente, su extensión a civiles que participaron del terrorismo de Estado, da cuenta justamente de una estructura semántica que es histórica, abierta e inconclusa y en la cual intervienen múltiples mediaciones simbólicas: estructuras de sentimiento, esquemas de género -el represor es siempre hombre-, mecanismos de esencialización, etc.

22 Si bien la lista de represores se dio a conocer en el informe de la CONADEP, sus integrantes decidieron finalmente no publicar los nombres en lo que sería la primera edición de Nunca Más.
} 
p.33). "la autopercepción del individuo-sujeto de la historia de vida [está siempre en] vinculación experiencial con el ambiente contextual” Y si bien, explica Salvi para el caso de los perpetradores, éstos suelen verse a sí mismos "tras la coraza protectora de un discurso construido" que se ancla en la defensa de la nación, la familia y los valores cristiano-occidentales (2010:81), en el conjunto de relatos analizados algunos oficiales parecieron haber incorporado ciertas expresiones del lenguaje de acusación y denuncia que circulaba socialmente al momento de pensar quiénes eran y qué habían hecho. En esta línea, en 1984 el ex oficial de la Armada Raúl Vilariño se definió a sí mismo con el término de "asesino" (Revista La Semana, 5 de enero de 1984) y diez años más tarde, en 1995, Scilingo definió su actuación en dictadura como propia de un “delincuente”. Esta fuerte carga negativa de las palabras elegidas para auto-referirse evidenció la intención de generar marcos de entendimiento con el público receptor de sus relatos pero también guardó relación con el reconocimiento relativo que hicieron del carácter ilegal de la represión. Retomando nuevamente las declaraciones de Scilingo, éste se definió como un delincuente porque, según sus términos, había actuado por fuera de las reglas y estructuras legales:

La Escuela Naval Militar me educó para ser oficial de Marina pero en la Escuela de Mecánica de la Armada me ordenaron actuar al margen de la ley y me transformaron en delincuente (Adolfo Scilingo, citado en VERBITSKY, 1995, p. 9)

Si bien estas narrativas no pueden ser pensadas como testimonios, en tanto no emergió un "yo" -un dar cuenta de sí mismo- que asumiera la responsabilidad por las propias decisiones y acciones (BACCl, 2016) en algunos casos -como en el de Scilingo- se observaron lapsus testimoniales. Ello no quiere decir que los perpetradores mostraran gestos de arrepentimiento ${ }^{23}$ sino que -muy excepcionalmente- exhibieron ciertas marcas

\footnotetext{
${ }^{23}$ Claudia Feld ha analizado el modo en que el periodismo de la época aplicó sobre los agentes de represión la figura del "arrepentido", pese a que en estos relatos no había indicios de tal actitud. Véase Feld, Claudia (2001). "La construcción del arrepentimiento: los ex represores en televisión" en Entrepasados, Buenos Aires, pp. 35 - 53. Más aún, el propio Scilingo se alejó de esa imagen construida por los medios de comunicación cuando señaló que: "tampoco quiero ser tan hipócrita de decir: yo soy el bueno ahora, que cuento esto. No. Porque el día de mañana van a decir "Scilingo el arrepentido". No es así. Scilingo, en las mismas circunstancias, hubiese hecho exactamente lo mismo. Pero todo ha ido cambiando, y en vez de contárselo como un triunfo, se lo cuento en una situación que ni se la puedo describir, gracias a mis superiores". Véase Verbitsky, Horario. El Vuelo, óp. cit. pág. 33.
} 
de perturbación (PAYNE, 2009) que ubican al lector de estos relatos ante "subjetividades ambiguas":

Hay cuatro cosas que me tienen mal. Los dos vuelos que hice, la persona que vi torturar y el recuerdo del ruido de las cadenas y los grillos. Los vi apenas un par de veces, pero no puedo olvidar ese ruido (...) Hay detalles que son importantes pero me cuesta contarlos. Lo pienso y me rayo (Adolfo Scilingo, citado en VERBITSKY, 1995, p. 9)

Si en Argentina se desarrolló a mediados de la década del noventa un clima político de contestación hacia las leyes de Obediencia Debida y Punto Final, en Uruguay, en cambio, primó una fuerte “cultura política consensual” (FREÍD, 2001) hacia el referéndum de $1989^{24}$. El Estado tampoco motorizó la conformación de una comisión de la verdad y cuando en septiembre de 1989 el Servicio de Paz y Justicia (SERPAJ) publicó el informe Uruguay Nunca Más -sin ayuda alguna del Estado-, éste tuvo un alcance y difusión limitados, según Funes (2001), producto del contexto de derrota en que salió la primera edición.

Esta política institucional de "dejar atrás" el pasado dictatorial, si bien enmarcó la lucha de los organismos de derechos humanos en un clima de fracaso y desazón, en modo alguno implicó su desactivación. En julio de 1996 se conformó un grupo de "hijos de la dictadura" por impulso de una delegación de hijos argentinos que había viajado a Uruguay, y al poco tiempo comenzaron las acciones de escrache en distintos puntos del país. Claro está que la cantidad de miembros y de recursos simbólicos con que contó esta agrupación para viabilizar nuevos marcos de sentido sobre la figura de los agentes de represión no halló parangón con su homólogo argentino. Si durante 1995 la organización H.I.J.O.S de Argentina había crecido de 350 a 600 miembros, para el año 1998 la red construida en Uruguay no superaba la veintena de integrantes (FREÍD, 2001)

Es en este escenario, de memoria y olvido a la vez, que el otrora jefe de Fusileros Navales se definió como un "profesional de la violencia” (El Espectador, 23 de septiembre de 1996), alejándose de las categorías de "asesino" o "delincuente" que usaron sus pares argentinos para definirse. Esta valoración positiva que hizo de sí mismo debe ser puesta

\footnotetext{
24 En 1989 los organismos de derechos humanos lograron que la Ley de Caducidad fuera sometida a un
} plebiscito; sin embargo, un $54 \%$ de los ciudadanos uruguayos terminó votando por la vigencia de la ley. 
en relación con su mirada sobre el terrorismo de Estado en Uruguay, como una lucha “antisubversiva” que buscó apartarse lo menos posible de las normas y leyes establecidas. Partiendo de esa concepción de la violencia estatal y de sí mismo, cuando se manifestó públicamente no lo hizo desde la victimización sino mostrándose como un locutor válido. Justamente, el título de la carta con la que Tróccoli irrumpió por primera vez en la escena pública -"Yo asumo, yo acuso"- además de remitirnos al universo de sentidos contenido en el J'accuse.... de Émile Zolá, reveló la posición desde la cual este militar pensó su rol en dictadura. Ni el relato que hilvanó formó parte de una "confesión" ni el relator se aproximó a la figura del "arrepentido".

\section{Colofón}

El estudio de este conjunto de relatos puso de relieve las distintas miradas que agentes de represión elaboraron de su participación en el terrorismo estatal. En ese ejercicio retrospectivo intervino la inscripción nacional de estos agentes en dos países, como Argentina y Uruguay, con identidades colectivas, prácticas de memoria y sensibilidades distintas.

Si bien los noventa fueron años de impunidad en relación al tratamiento jurídico de los crímenes de Estado, en la coyuntura que aquí se analizó las declaraciones públicas de agentes de represión marcaron un punto de inflexión y volvieron a instalar el pasado en el presente. Estas declaraciones mostraron singularidades y patrones comunes en los modos de pensar la propia actuación en dictadura. Si en Uruguay Tróccoli invocó el compromiso ideológico y la legalidad del sistema represivo como aspectos centrales para tornar inteligible su posición en el terror, los relatos aquí estudiados de militares argentinos, por su parte, tendieron a enarbolar el principio de obediencia -por sobre el de compromiso- y a reconocer la ilegalidad de la represión.

Estas diferencias no remiten solamente a la naturaleza de los aparatos represivos sino también al rol de los derechos humanos en los procesos de reconstrucción democrática. En Uruguay, la falta de políticas públicas para promover memoria, verdad y justicia configuraron el escenario político y social de las declaraciones de Tróccoli, las 
cuales se anclaron en la convicción ideológica y en el no reconocimiento de las tramas ilegales de la represión. En el caso de los relatos de perpetradores argentinos, la afirmación de sí mismos como oficiales obedientes compuso el núcleo de una narrativa que fue forjándose desde inicios de los '80 al calor de los conflictos por la judicialización de las responsabilidades, y que se afianzó a mediados de los '9o ante la posibilidad incierta o el temor nunca despejado de una reactivación de los juicios por delitos de Lesa Humanidad. De igual modo, el reconocimiento relativo que hicieron de la ilegalidad del sistema desaparecedor seguramente tuvo que ver con un discurso que necesariamente debió ceder a fin de generar las condiciones de escucha en una sociedad renuente al olvido.

\section{Referencias}

ALONSO, Luciano. Modos de dominación y regímenes de violencia en las dictaduras iberoamericanas. Un esbozo de comparación en e-I@tina, v.5, n.7, julio-septiembre, 2007.

ANSALDI, Waldo. La democracia en América Latina: un barco a la deriva.Buenos Aires: FCE, 2007.

ANSALDI, Waldo; GIORDANO, Verónica. La construcción del orden en América Latina. Buenos Aires: Ariel, 2012.

Autocrítica del General Martín Balza, 25/04/1995.

BACCI, Claudia. Numeralia: ¿cuántas voces guarda un testimonio? Constelaciones: Revista de Teoría Crítica, 2016. p.528-536.

BLIXEN, Samuel. ¿Quién es Jorge Néstor Tróccoli? Equipo Nizkor, 1996. En línea: <http://www.derechos.org/nizkor/uruguay/troccoli2.html>. Acesso em: 10/05/1996.

CRENZEL, Emilio. La historia política del nunca más. Buenos Aires: Siglo XXI, 2008.

Declaración de los tres comandantes en Jefe de las FF.AA de Uruguay, 1986. 
“Declaración de Omar Riveros” en La Prensa, (28/12/1980).

DUBET, Francois. Sociología de la experiencia. Madrid: Complutense, 1998.

El Espectador, 23/09/1996.

Entrevista a Hugo Medina, Semanario Búsqueda, 7 de marzo de 1991, disponible en http://www.espectador.com/documentos/Reportaje.pdf

Entrevista a Raúl Vilariño, Revista La Semana, año VI, número 370, 5/01/1984

Entrevista al ex sargento Víctor Ibáñez. Diario La Prensa, 25/04/1995

FEIERSTEIN, Daniel. Terrorismo de Estado y genocidio en América Latina. Buenos Aires: Prometeo, 2009

FELD, Claudia. La construcción del arrepentimiento: los ex represores en televisión. En: Entrepasados: Buenos Aires, 2001, p. 35 - 53.

FELD, Claudia. Memoria colectiva y espacio audiovisual: historia de las imágenes del Juicio a las ex Juntas Militares (1985-1998) En: GROPPO, Bruno; FLIER, Patricia (Comps.). La imposibilidad del olvido: recorridos de la memoria en Argentina, Chile y Uruguay. Buenos Aires-La Plata: Al Margen-BDIC, 2001.

FERRAROTTI, Franco. Las historias de vida como método. Convergencia: Revista de Ciencias Sociales, v 14, n. 44, mayo-ago., 2007.

FRANCO, Marina. El complejo escenario de la disolución del poder militar en la Argentina: la Autoamnistía de 1983. Contenciosa, año I, n.2, 2014.

FREÍD, Gabriela. Memorias que insisten: la intersubjetividad de la memoria y los hijos de desaparecidos por la dictadura militar argentina (1976-1983).En: GROPPO, Bruno; FLIER, Patricia (Comps.). La imposibilidad del olvido: recorridos de la memoria en Argentina, Chile y Uruguay. Buenos Aires-La Plata: Al Margen-BDIC, 2001

Funes, Patricia. "Nunca más. Memorias de las dictaduras en América Latina. Acerca de las Comisiones de Verdad en el Cono Sur" en Groppo, Bruno y Flier, Patricia. La imposibilidad del olvido. Recorridos de la memoria en Argentina, Chile y Uruguay, La Plata, Al Margen/Bibliotheque de Documentation Internationale Contemporaine. 2001.

Jefe de las FF.AA de Uruguay, 1986. 
JENSEN, Silvina. Los exiliados: la lucha por los derechos humanos durante la dictadura. Buenos Aires: Editorial Sudamericana, 2010.

MARTIN, Lucas . Dictadores preocupados: El problema de la verdad durante el Proceso (1976-1983). Revista Postdata, v.15, n.1., 2010.

PAYNE, Leigh. Testimonios perturbadores: ni verdad ni reconciliación en las confesiones de violencia de estado. Bogotá: Ediciones Uniandes, 2009.

ROMERO, Luis Alberto. Breve historia contemporánea de la Argentina. Buenos Aires: Fondo de Cultura Económica, 1994.

SALVI, Valentina .Dice lo que ya no puede ser negado. Página 12, (02/05/2012a). Disponible en: <http://www.pagina12.com.ar/diario/elpais/1-193083-2012-05-02.html>. Acesso em:

SALVI, Valentina Entelequia. Enmascaramiento y disimulo: las últimas declaraciones de Videla sobre los desaparecidos (1998-2012).Rúbrica Contemporánea, v. 5, n.19, 2016.

SALVI, Valentina. De vencedores a víctimas: memorias militares sobre el pasado reciente en la Argentina, Buenos Aires: Editorial Biblos, 2012b.

SALVI, Valentina. Interrogantes sobre el valor de la palabra. Violencia y narración. Tempo e Argumento, v.2, n.1, p.71-85, enero-jun., 2010

SALVI, Valentina.Los represores como objeto de estudio: obstáculos, problemas y dificultades para su investigación en Argentina. Cuadernos del IDES, n 32, mayo, 2016.

SLATMAN, Melisa. Una doctrina contrarrevolucionaria para el ejército argentino. Análisis de la discursividad oficial del Ejército Argentino durante la Guerra Fría (1957-1976) En: GARCÍA FERREIRA, Roberto (Comp.). Guatemala y la Guerra Fría en América Latina (1947-1977. Guatemala: CEUR-USAC, 2010.

TCACH, César; SERVETTO, Alicia. En el nombre de la patria, el honor y los Santos Evangelios: las dictaduras militares en Argentina y Uruguay. En: REY TRISTÁN, Eduardo (Dir.). Memorias de la Violencia en Uruguay y Argentina: Golpes, dictaduras y exilios (1973-2006). Santiago de Compostela: Universidad de Santiago de Compostela, 2007.

Tróccoli, Néstor "Yo asumo, yo acuso", El País, 5/05/1996.

Tróccoli, Néstor. La ira del Leviatán. Del método de la furia a la búsqueda de la paz", y abarca el período 1963-1996, Montevideo, Caelúm, 1996. 
VEZZETTI, Hugo .Verdad jurídica y verdad histórica. Condiciones, usos y límites de la figura del genocidio. En: HILB, C., Saazar, P. J.; MARTíN, L (Eds.). Lesa humanidad. Argentina y Sudáfrica: reflexiones después del Mal, Buenos Aires: Katz, 2014.

VEZZETTI, Hugo. Pasado y presente: Guerra, dictadura y sociedad en la Argentina. Buenos Aires: Siglo XXI Editores, 2002. 